\title{
Analisis Faktor Kunjungan Wisata Sejarah di Kepulauan Seribu Jakarta
}

\author{
Annisa Retno Utami ${ }^{1}$, Farida $^{2}$ \\ 1,2Universitas Sahid Jakarta, annisaretno4@gmail.com
}

\begin{abstract}
ABSTRAK
Indonesia menjadi salah satu negara yang berkembang pada bidang pariwisata. Pariwisata yang sebagain besar dimiliki oleh Indonesia yaitu wisata bahari. Potensi wisata bahari yang banyak dikenal dan dikunjungi oleh wisatawan salah satunya wisata bahari di Kepulauan Seribu Jakarta. Di Kepulauan Seribu terdapat wisata sejarah yaitu adalah Pulau Kelor, Pulau Cipir dan Pulau Onrust. Pada pulau wisata sejarah ini memiliki daya tarik tersendiri pada masing-masing pulaunya, namun belum dikembangkan oleh pengelola objek wisata. Penelitian ini bertujuan untuk melakukan analisis faktor kunjungan wisata sejarah di Kepulauan Seribu Jakarta. Metode dalam penelitian ini dengan metode deskripsi analisis dengan perhitungan data menggunakan SPSS. Berdasarkan hasil penelitian wisatawan banyak tertarik untuk mengunjungi Pulau Kelor karena terdapat bangunan peninggalan sejarah yaitu Benteng Martello sedangkan pada variabel faktor kunjungan hasil tertinggi pada Faktor biaya dan hasil terendah pada Faktor Keluarga dan Pengalaman. Sampel yang digunakan pada penelitian ini yaitu sebanyak 100 responden.
\end{abstract}

Kata Kunci: Wisata Sejarah, Faktor Kunjungan Wisatawan, Wisata Sejarah Kepulauan Seribu, Pariwisata

\begin{abstract}
Indonesia has become one of the developing countries in the tourism sector. Tourism is mostly owned by Indonesia, namely marine tourism. The potential of marine tourism is widely known and visited by tourists, one of them is marine tourism in the Thousand Islands, Jakarta. In the Thousand Islands there are historical attractions namely Kelor Island, Cipir Island and Onrust Island. In this historical tourism island, it has its own attraction on each island, but has not been developed by the manager of the tourist attraction. This study aims to conduct a factor analysis of historical tourist visits in the Thousand Islands Jakarta. The method in this study is the description analysis method with data calculation using SPSS. Based on the results of research many tourists are interested in visiting Kelor Island because there is a historical heritage building, Martello Fortress while the highest visiting factor variable is the cost factor and the lowest yield is the Family and Experience Factor. The sample used in this study was 100 respondents
\end{abstract}

Keywords: Historical Tourism, Tourist Visit Factors, Thousand Islands Historical Tourism, Tourism

Diterima: 8 Agustus 2019, Direvisi: 2 November 2019, Diterbitkan: 15 Februari 2020. 


\section{PENDAHULUAN}

Pada tahun 2009, pariwisata di Indonesia menepati urutan ketiga dalam penerima devisa setelah minyak, gas bumi dan kelapa sawit. Pariwisata merupakan sektor yang potensial apabila dilakukan pengembangan karena dapat menambah sumber pendapatan daerah, sehingga dapat membantu perkembangan ekonomi daerah setempat.

Spillane (2004:14) mengatakan bahwa pada pembangunan sektor pariwisata menyangkut aspek sosial budaya, ekonomi dan politik. Pernyataan tersebut sejalan dengan adanya Undang-Undang Nomor 10 tahun 2009 Tentang Kepariwisataan yang menyatakan bahwa Penyelenggaraan Kepariwisataan ditujukan untuk meningkatkan pendapatan nasional dalam rangka meningkatkan kesejahteraan dan kemakmuran rakyat, memperluas dan memeratakan kesempatan berusaha dan lapangan kerja, mendorong pembangunan daerah, memperkenalkan dan mendayagunakan objek dan daya tarik wisata di Indonesia serta memupuk rasa cinta tanah air dan mempererat persahabatan antar bangsa.

Indonesia merupakan salah satu negara yang berkembang di bidang pariwisata. Pariwisata di Indonesia sebagian besar yaitu wisata bahari, karena Indonesia merupakan negara yang terdiri dari kepulauan dan Indonesia terletak diantara dua benua besar yaitu benua Asia dan Australia.

Indonesia memiliki banyak potensi wisata yang saat ini belum dikembangkan secara maksimal, salah satunya potensi wisata sejarah yang berada di Kepulauan Seribu Jakarta. Kepulauan Seribu merupakan bagian dari Kotamadya Jakarta Utara yang ditingkatkan statusnya menjadi Kabupaten Administrasi Kepulauan Seribu dengan maksud untuk meningkatkan pelayanan dan kesejahteraan masyarakat serta pengolahan Kepulauan Seribu dari segala aspek, antara lain kelestarian lingkungan, konservasi sumber daya alam, ekonomi, kesejahteraan rakyat dan sosial budaya. Pemerintah Kabupaten Administrasi Kepulauan Seribu mengungkapkan bahwa saat ini pengembangan kepulauan tersebut masih mengalami sejumlah kendala, terutama masalah infrastrukturnya. Selain masalah infrastruktur, pelaku usaha wisata di Kepulauan Seribu juga menilai bahwa jasa angkutan umum transportasi untuk menuju pulau tersebut masih belum berjalan dengan baik.

Saat ini pulau wisata sejarah yang berada di Pulau Seribu Jakarta belum di optimalisasikan secara maksimal oleh pengelola objek wisata,
Pulau tersebut adalah Pulau Kelor, Pulau Cipir dan Pulau Onrust. Banyak wisatawan yang belum mengetahui Pulau Sejarah yang ada di Kepulauan Seribu ini, karena pulau ini belum terlalu di kenal oleh wisatawan seperi halnya Pulau Tidung, Pulau Pari, Pulau Harapan dan Pulau Untung Jawa. Pulau yang berada di Pulau Seribu Jakarta ini masing-masing memiliki keunikan dan ciri khas tersendiri, seperti halnya Pulau Sejarah ini memiliki ciri khas yaitu pada bangunan sejarahnya.

Pulau Kelor yang memiliki ciri khas sejarahnya pada bekas benteng pertahanan VOC yang dibangun untuk melawan serangan kapal-kapal bangsa Portugis pada abad ke-17. Selain itu di Pulau Kelor terdapat bangunan Benteng Martello yang pada masa penjajahan Belanda merupakan benteng pertahanan bagi wilayah perairan Teluk Jakarta dan saat ini benteng tersebut menjadi ciri khas dari pulau tersebut.

Pulau sejarah selanjutnya yaitu Pulau Cipir yang memiliki ciri khas pada bangunan sejarah masa galangan kapal VOC dan terdapat sisa-sisa dari bangunan Karantina Haji pada tahun 1911-1933. Saat berkunjung ke Pulau Cipir wisatawan masih bisa melihat sisa-sisa bangunan reruntuhan bekas barak haji, rumah sakit, hingga tempat penampungan khusus calon jemaah haji yang terkena penyakit menular.

Tujuan terakhir yaitu Pulau Onrust yang menyimpan sejarah paling panjang dibandingkan kedua pulau sebelumnya. Pada abad ke-17 dan 18, Pulau Onrust digunakan sebagai pelabuhan utama VOC sekaligus tempat perbaikan kapal sebelum akhirnya dipindahkan ke Tanjung Priok. Pada zaman penjajahan Jepang, pulau ini dijadikan penjara bagi tahanan politik, sehingga saat ini terdapat bangunan bekas penjara saat itu. Di Pulau Onrust wisatawan juga bisa menemukan sisa peninggalan arkeologi pada masa Belanda dan terdapat sisa bangunan sebuah rumah yang masih utuh yang saat ini dijadikan sebagai Museum, serta terdapat bekas pemakaman Belanda.

Potensi wisata sejarah di Kepulauan Seribu dapat dikembangkan dengan adanya bantuan dari pihak-pihak terkait seperti pemerintah daerah Kepulauan Seribu dan masyarakat lokal untuk melakukan perbaikan dan mengelola objek wisata tersebut. Saat ini banyak tour and travel yang melakukan open trip untuk berkunjung ke pulau sejarah di Kepulauan Seribu dengan one day trip pada hari-hari weekend (sabtu-minggu) dengan biaya yang cukup terjangkau Rp 70.000 - Rp 100.000. Untuk menarik minat wisatawan saat ini 
masyarakat lokal sudah menyediakan fasilitas. atraksi wisata seperti membuka permainan air banana boat dan donat serta penyewaan float yang dapat digunakan oleh wisatawan untuls. berfoto-foto. Sudah banyak warung-warung yang dikelola oleh masyarakat lokal untuk menyediakan makan minum wisatawan ketika melakukan perjalanan wisata ke pulau sejarah tersebut.

Tujuan penelitian ini yaitu untuk mengetahui faktor-faktor yang mempengaruhi wisatawan dalam mengunjungi Pulau Wisata Sejarah di Kepulauan Seribu Jakarta.

\section{KAJIAN LITERATUR Industri Pariwisata}

Industri pariwisata bukanlah industri yang dapat berdiri sendiri, tetapi merupakan suatu industri yang terdiri dari serangkaian perusahaan yang menghasilkan jasa atau produk yang berbeda antara yang satu dengan yang lainnya (Schmool dalam Khasani, 2014). Namun perbedaaan tersebut tidak hanya dalam jasa yang dihasilkan saja, tetapi juga dalam besarnya perusahaan, lokasi tempat kedudukan, organisasi yang mengelola dan metode pemasarannya (Tahwin, 2003).

Badrudin (2001) mengatakan bahwa dalam industri pariwisata terdapat lima unsur yang sangat penting, yaitu :
a. Attractions (daya tarik)
b. Facilities (Fasilitas yang diperlukan)
c. Infrastructure (Infrastruktur)
d. Transportations (Transportasi)
e. Hospitality (Keramahtamahan)

\section{Faktor Yang Mempengaruhi Perjalanan Wisata}

Khasani (2014), faktor-faktor utama yang yang mempengaruhi perjalanan wisata adalah sebagai berikut :

1. Profil Wisatawan (Tourist Profile)

Profil wisatawan dikelompokan menjadi 2 (dua) kategori, yaitu :

a. a. Karakteristik sosial ekonomi wisatawan (Sosio-economic characteristic) yang meliputi umur, pendidikan, dan tingkat pendapatan.

b. b. Karakteristik tingkah laku (Behavioral characteristic) yang meliputi motivasi, sikap dan keinginan wisatawan.

2. 2.Pengetahuan untuk melakukan perjalanan (travel awareness) yang meliputi informasi tentang daerah tujuan wisata serta ketersediaan fasilitas dan pelayanannya.
3. Karakteristik perjalanan (trip features) yang meliputi jarak, waktu tinggal di daerah tujuan, biaya dan waktu perjalanan.

4. Sumber daya dan karakteristik daerah tujuan (resources and characteristic of destination) yang meliputi jenis atraksi, akomodasi, ketersediaan dan kualitas fasilitas pelayanan, kondisi lingkungan dan sebagainya.

\section{Model Proses Keputusan Perjalanan}

Schmoll (Cooper et.al, Swarbrooke dan Horner) dalam Ismayanti (2010:27) membuat sebuah model keputusan perjalanan wisata yang harus dilihat secara menyeluruh berdasarkan motivasi, keinginan, kebutuhan dan pengharapan wisatawan secara personal dan sosial. Proses keputusan perjalanan wisata terdiri dari empat bidang yang mempengaruhi keputusan akhir, yaitu :

1. Stimulan Wisata

Stimulan wisata merupakan hal-hal yang membuat seseorang terpengaruh untuk berwisata, seperti iklan, promosi, buku-buku, saran teman, publikasi, dan sumber lain.

2. Variabel Internal

Variabel internal berasal dari dalam diri seseorang wisatawan meliputi sosio ekonomi, kepribadian, pengaruh nilai dan sikap. Keseluruhan unsur dalam variabel internal memunculkan motivasi, kebutuhan dan pengharapan wisata.

3. Variabel Eksternal

Variabel eksternal berasal dari luar diri seseorang wisatawan yang meliputi citra destinasi, pengalaman, tujuan perjalanan, ketersediaan waktu, dan biaya.

4. Karakteristik Daerah Tujuan Wisata

Karakteristik daerah tujuan wisata yaitu manfaat yang didapatkan atas biaya yang ditawarkan, atraksi atau daya tarik dan kualitas serta kuantitas, pengaturan perjalanan, dan peluang untuk berwisata.

\section{METODOLOGI PENELITIAN \\ Operasional Variabel}

Pada penelitian ini operasional variabel dijadikan sebagai panduan dalam melakukan tahap penelitian dalam hal pencarian data dari responden. Variabel pada penelitian ini yaitu faktor-faktor yang mempengaruhi kunjungan wisatawan di Pulau Seribu Jakarta yang kemudian diolah data tersebut menggunakan SPSS untuk melihat faktor tertinggi dan faktor terendah, yang dimaksud dari masing-masing variabel pada penelitian ini yang terdiri dari : 
1. Promosi (X1)

2. Motivasi (X2)

3. Kebutuhan (X3)

4. Keinginan berwisata (X4)

5. Pendapatan/Gaji (X5)

6. Ketersediaan Biaya (X6)

7. Jarak (X7)

8. Keluarga (X8)

9. Transportasi (X9)

10. Fasilitas (X10)

11. Informasi Tujuan Wisata (X11)

12. Pelayanan (X12)

13. Pengalaman (X13)

14. Harga (X14)

15. Atraksi Wisata (X15)

16. Pengaturan Perjalan Wisata (X16)

17. Kondisi Lingkungan (X17)

18. Kualitas Fasilitas Wisata (X18)

\section{Jenis Data dan Sumber Data}

\section{Data Primer}

Data yang diperoleh secara langsung dari obyek yang diteliti melalui riset lapangan secara langsung. Dalam penelitian ini, yang termasuk data primer yaitu data yang diperoleh dari hasil wawancara dengan pihak pengelola objek wisata dan hasil kuisioner yang diisi oleh wisatawan yang berkunjung ke Pulau Wisata Sejarah di Kepulauan Seribu (Pulau Kelor, Pulau Cipir dan Pulau Onrust)

\section{Data Sekunder}

Merupakan data yang dikumpulkan, diolah dan diterbitkan oleh pihak lain yang diperoleh dari instansi terkait serta berbagai sumber pustaka lainnya yang memuat berbagai teori-teori maupun bahan referensi mengenai sejarah perusahaan dan gambaran umum objek wisata.

\section{Populasi dan Sampel}

Populasi merupakan objek dan subjek yang ada pada suatu wilayah yang telah memenuhi syarat tertentu yang berkaitan dengan permasalahan pada penelitian. Sehingga pada penelitian ini yang menjadi populasi adalah wisatawan yang berkunjung ke Pulau Wisata Sejarah di Kepulauan Seribu (Pulau Kelor, Pulau Cipir dan Pulau Onrust).

Sedangkan untuk sampel pada penelitian ini dapat diukur dengan menggunakan jumlah sampel minimal yang digunakan. Menurut Kusnendi (2008:54) ukuran pada sampel minimal yang dilakukan dalam penelitian yaitu dengan mengukur jumlah indikator dikali dengan 5 (lima) konstruk. Sehingga pada penelitian ini terdapat 19 indikator, jadi sampel yang digunakan pada penelitian ini yaitu 19 x $5=95$ atau dibulatkan menjadi 100 responden.

Dalam menentukan sampel akan dilakukan dengan teknik purposive sampling yaitu memilih orang yang dianggap mewakili yaitu wiasatawan atau orang yang telah mengunjungi Pulau Wisata Sejarah (Pulau Kelor, Pulau Cipir dan Pulau Onrust). Hasil penelitian yang di dapat kemudian dilakukan dengan metode analisis setelah data penelitian di olah dengan SPSS, kemudian di sajikan dalam bentuk grafik pada masing-masing faktornya.

\section{HASIL DAN PEMBAHASAN \\ Sejarah Pulau Kelor}

Pulau Kelor merupakan pulau yang berada di Kepulauan Seribu, Jakarta. Pulau Kelor merupakan salah satu Pulau Sejarah di Kepulauan Seribu. Pada Pulau Kelor memiliki banyak menyimpan sejarah pada jaman penjajahan Belanda. Di namakan Pulau Kelor karena pulau ini memiliki ukuran yang kecil sehingga penduduk setempat mengibaratkan pulau ini selebar daun kelor, sehingga pulau ini dikenal dengan sebutan Pulau Kelor.

Jika dilihat dari dekat Benteng Martello ini sungguh luar biasa, meskipun hanya tinggal reruntuhan namun benteng ini masih sangat kokoh, berwibawa, yang terbuat dari bahan bata merah yang berukuran besar. Yang saat ini terlihat hanya tinggal lapisan bata merahnya saja, sementara campuran semen yang melapisinya hampir semua sudah rontok. Jika dilihat dari struktur permukaan yang berupa bata-bata merah dan bentuk keseluruhan dari benteng ini memang sangat indah dan menjadi salah satu daya tarik tersendiri ketika wistawan berkunjung ke Pulau Kelor ini. Banyak wisatawan yang mengabadikan benteng ini dengan berfoto-foto. Berikut gambar dari Benteng Martello yang menjadi daya tarik di Pulau Kelor. 

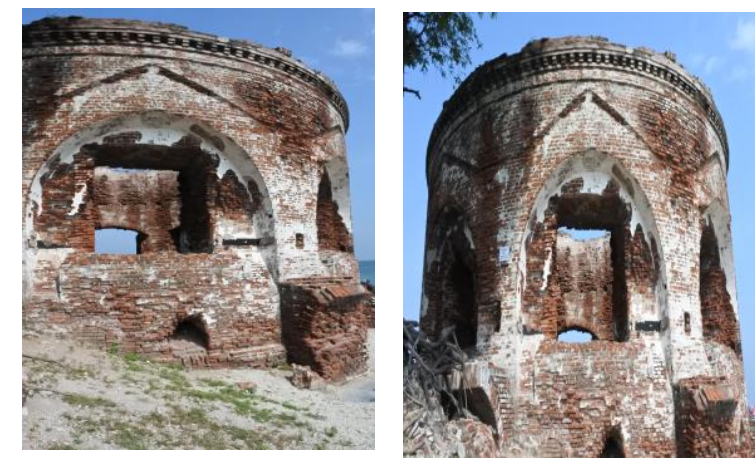

Gambar 1. Benteng Martello

Benteng Martello ini cukup luas, bangunan bundar yang sekarang ada hanyalah pusat atau titik tengah dari keseluruhan benteng. Sebelum terjadinya abrasi ada tembok besar yang berjarak 100 meter dari pusatnya yang mengelilingi menara utama, namun setelah terjadinya abrasi kini benteng ini hanya berjarak beberapa langkah saja dari bibir pantai.

Pada zaman dahulu, serdadu Belanda menggunakan Pulau Kelor sebagai garda terdepan dalam mempertahankan Batavia dari serangan Portugis. Ada tiga Benteng Martello yang dibangun, dua diantaranya terdapat di Pulau Onrust dan Pulau Bidadari. Namun hanya yang terdapat di Pulau Kelor yang tersisa. Bentuk Benteng Martello yang bundar menguntungkan pihak Belanda dalam mempertahankan daerah kekuasaan mereka. Apalagi saat ditunjang oleh senjata yang dapat bergerak melingkar 360 derajat. Benteng ini merupakan salah satu korban terjangan tsunami akibat letusan dahsyat Gunung Krakatau tahun 1883.

Selain benteng, pada Pulau Kelor terdapat cerita menarik lainnya. Pulau ini kerap disebut sebagai Pulau Kuburan, sebab pada zaman dahulu para tahanan politik yang di hukum mati di Pulau Onrust dan Pulau Cipir, dikubur di Pulau Kelor. Masyarakat sekitar juga menyebut pulau ini sebagai Pulau Kuburan

\section{Sejarah Pulau Cipir}

Nama asli dari Pulau Cipir ini adalah Pulau Kuyper, namun orang-orang lebih mengenalnya dan menyebutnya dengan Pulau Cipir atau Pulau Khayangan. Dahulu Pulau Cipir terkenal dengan tempat penyimpanan berbagai kebutuhan para kolonialis. Selain itu Pulau Cipir ini merupakan pulau yang lahannya bekas rumah sakit untuk perawatan dan karantina penyakit menular bagi para jemaah haji pada tahun 1911-1933, Pulau Onrust dan Pulau Cipir digunakan sebagai pusat karantina haji. Semua para jemaah haji Indonesia yang ingin naik haji dipusatkan di pulau ini terlebih dahulu.

Para jemaah haji di karantina untuk menjalani pemeriksaan kesehatan dan jika ada yang sakit akan dirawat dahulu. Pada jaman dahulu banyak pasien karantina haji yang sakit dan disuntik mati di pulau ini. Setelah mereka selesai pergi haji, mereka harus dikarantina kembali di Pulau Cipir untuk melakukan pemeriksaan.

Setelah Belanda hengkang, sejarah di pulau ini terbengkalai. Pada masa orde baru, pulau ini menjadi tempat karantina, namun kali ini bukan untuk jemaah haji tetapi untuk para penderita TBC dan kusta (lepra). Mereka diangkut ke pulau ini bukan untuk disembuhkan, namun sengaja diasingkan agar penyakit yang mereka derita tidak mudah menular.

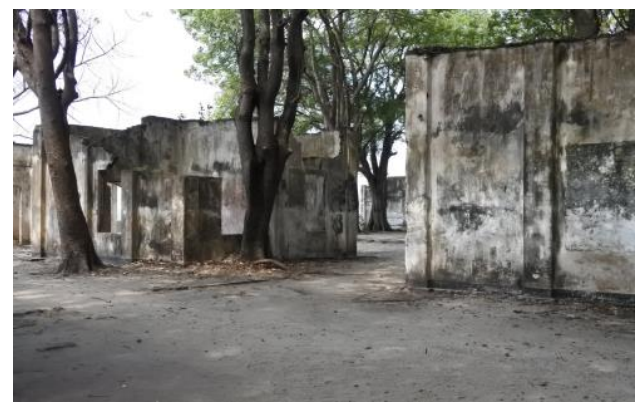

Gambar 2. Pulau Cipir

\section{Pulau Onrust}

Pulau Onrust merupakan salah satu pulau di Kabupaten Kepulauan Seribu, Jakarta yang letaknya berdekatan dengan Pulau Bidadari. Pada masa kolonial Belanda, rakyat sekitar menyebut Pulau ini dengan sebutan Pulau Kapal, karena pada waktu itu pulau ini sering dikunjungi oleh kapal-kapal Belanda sebelum menuju Batavia. Dalam pulau ini masih banyak terdapat peninggalan arkeologi pada masa kolonial Belanda dan juga rumah yang masih utuh dan dijadikan sebagai Museum Pulau Onrust.

Pulau Onrust menjadi salah satu objek wisata sejarah karena menyimpan masa lalu yang menarik. Dilansir dari pulauseribu.jakarta.go.id, berdasarkan arsip Taman Arkeologi Onrust, pulau ini pernah menjadi pusat bongkar muat komuditas dagang dan galangan kapal VOC Belanda. Awalnya, pulau Onrust digunakan oleh raja-raja Banten sebagai tempat istirahat. Namun kemudian terjadi sengketa antara Kerajaan Banten dan Jayakarta sehingga tidak pernah ada upaya penyelesaian. Jayakarta merasa memiliki pulau ini karena lokasinya dekat (di hadapan Kota Jayakarta), sedangkan Banten 
mempunyai hak atas pulau tersebut sebab seluruh Kepulauan Seribu merupakan bagian dari teritorial kekuasaannya. Saat Belanda datang dan gagal memonopoli perdagangan di Banten, mereka kemudian mengalihkan perhatiannya ke Jayakarta.

Di masa penjajahan Belanda, pulau Onrust juga menjadi lokasi pemberangkatan jemaah haji Indonesia menuju Arab Saudi. Belum majunya teknologi pesawat, membuat mereka harus pergi ke tanah suci melalui jalur laut. Di Pulau Onrust masih dijumpai sisa sisa reruntuhan bangunan barak asrama haji. Konon pulau ini juga merupakan tempat karantina penyakit menular yang terbawa jemaah haji. Lain halnya dengan Belanda, saat Jepang menjajah Indonesia, Pulau Onrust pun berubah fungsi. Dilansir dari Kompas.com, setelah Jepang masuk, pulau ini beralih fungsi menjadi tempat pengasingan tahanan politik dan orang-orang yang dianggap pemberontak. Terdapar barak penjara sekitar 1,5 meter dengan atap seng dan kawat berduri di sana.

\section{Faktor Yang Mempengaruhi Kunjungan Wisatawan ke Pulau Sejarah}

Dari 19 variabel yang digunakan dalam penelitian ini, dari 19 variabel tersebut faktor yang tertinggi yang mempengaruhi kunjungan wisatawan ke Pulau Sejarah yaitu variabel X15 sebesar $87 \%$ mengenai Harga. Berdasarkan hasil wawancara dengan wisatawan Faktor Harga Wisata yang murah menjadi daya tarik wisatawan untuk mengunjungi Wisata Sejarah. Wisatawan hanya perlu membayar sebesar Rp 70.000,- sudah dapat mengunjungi 3 tempat objek wisata sejarah di Kepulauan Seribu, selain itu sudah dapat menikmati wisata pantai, biaya transportasi, tiket masuk objek wisata.

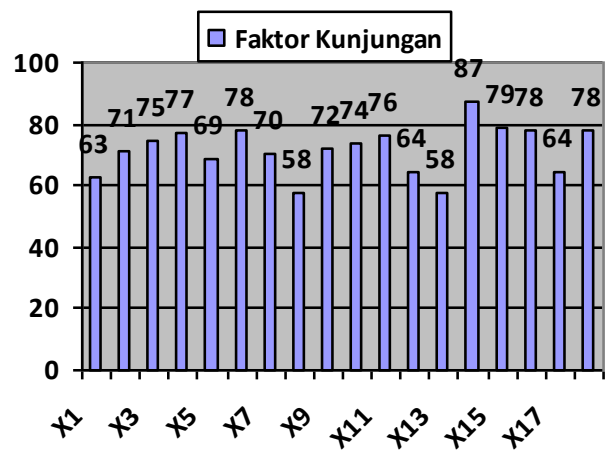

Gambar 3. Faktor Kunjungan

Selain faktor Harga, faktor tertinggi kedua setelah harga adalah variabel X16 sebesar 79\% mengenai Araksi Wisata. Ketika wisatawan berkunjung pada Wisata Sejarah di Kepulauan Seribu, wisatawan dapat menikmati atraksi wisata yang ada seperti dengan melihat bangunan bersejarah yang ada di Pulau Kelor mengenai benteng Martelo yang menjadi salah satu icon pada wisata sejarah di Kepulauan Sejarah. Di benteng ini wisatawan dapat berfoto-foto sambil menikmati udara di pinggir pantai.

Selain atraksi wisata bangunan sejarah wisatwan juga dapat menikmati sejuknya angin pantai di masing-masing pulau sejarah, karena masingmasing pulau sejarah ini terletak berdekatan dan berada di tengah laut sehingga pinggiran dari wisata ini yaitu lautan.

Di Pulau Cipir \& Kelor terdapat atraksi wisata air, seperti permainan banan boad, floating yang umumnya digunakan oleh wisatawan untuk berfoto-foto. Banyak juga wisatawan yang berenang di pinggir pantai ini, sehingga bukan hanya wisata sejarah saja yang didapat oleh wisatawan tetapi wisatawan juga dapat menikmati wisata pantai.

Sedangkan untuk hasil faktor terendah pada faktor Keluarga dan Pengalaman sebesar 58\%. Berdasarkan hasil wawancara wisatawan yang datang ke Pulau ini umumnya tidak bersama keluarga tapi bersama teman karena untuk berkunjung ke Pulau ini rata-rata wisatawan mengikuti kegiatan open trip agar biaya perjalannya lebih murah.

Selain itu untuk faktor Pengalaman, umumnya wisatawan yang berkunjung belum memiliki pengalaman dalam berwisata ke Pulau Sejarah ini, sehingga rata-rata dari hasil penelitian ini $89 \%$ wisatawan yang berkunjung yaitu merupakan kunjungan yang pertama kali, sedangkan $11 \%$ wisatwan yang sudah pernah berkunjung ke Pulau Sejarah ini.

\section{KESIMPILAN DAN REKOMENDASI}

Berdasarkan hasil penelitian mengenai Wisata Sejarah di Kepulauan Seribu ini pada masingmasing pulau memiliki keunikan serta daya tarik tersendiri. Umumnya wisatawan tertarik berkunjung ke Pulau Sejarah ini karena ingin melihat benteng martello yang menjadi salah satu icon daya tarik. Di benteng ini wisatawan dapat berfoto-foto untuk mengabadikan bangunan sejarah ini, selain bangunan wisatawan tertarik untuk datang karena dapat juga menikmati wisata pantai di pulau sejarah ini. Sedangkan untuk hasil penelitian pada faktor-faktor yang mempengaruhi kunjungan wisata hasil faktor tertinggi pada 
faktor Harga dan faktor terendah pada faktor Keluarga dan Pengalaman.

Saran penelitian ini yaitu diperlukannya perbaikan atas sarana dan prasarana yang terdapat di wisata sejarah agar wisatwan merasa nyaman seperti salah satuna toilet. Selain itu dapat ditambahkannya atraksi wisata yang menarik untuk dapat menambah daya tarik wisatawan untuk dapat berkunjung ke pulau wisata sejarah ini.

Rekomendasi yang diberikan pada penelitian ini untuk dilakukannya tambahan atraksi wisata untuk menarik wisatawan untuk datang ke Wisata Sejarah di Kepulauan Seribu. Selain atraksi wisata pengelola objek wisata atau pemerintahan Kepulauan Seribu untuk memperhatikan fasilitas yang ada seperti toilet umum yang terdapat di tempat wisata sejarah ini.

Rekomendasi untuk penelitian selanjutnya dapat mengukur mengenai kepuasan dan loyalitas wisatawan yang berkunjung ke Pulau Wisata Sejarah agar dapat dipergunakan sebagai masukan ke pengelola objek wisata untuk dilakukan perbaikan.

\section{DAFTAR PUSTAKA}

Spillane, JJ. 2004. Ekonomi Pariwisata Sejarah dan Prospeknya. Yogyakarta. Kanisius.

Undang-Undang Nomor 10 Tahun 2009 Tentang Kepariwisataan

Muhammad Tahwin. 2003. "Pengembangan Obyek Wisata Sebagai Sebuah Industri Studi Kasus Kabupaten Rembang," Jurnal Gemawisata, Vol. 1, No.3/November 2003, hal 236-249.

Ismayanti. 2010. Pengantar Pariwisata. PT. Gramedia Widisarana Indonesia

Khasani, M. Akrom. 2014. Analisis FaktorFaktor Yang Mempengaruhi Kunjungan Wisatawan Di Pantai Cahaya, Weleri, Kabupaten Kendal. Skripsi tidak di publikasi. Universitas Diponegoro.

Badrudin, Rudy. 2001 "Menggali Sumber Pendapatan Asli Daerah (PAD) Daerah Istimewa Yogyakarta Melalui Pengembangan Industri Pariwisata". Jurnal Kompak, Nomor 3, Halaman 38440 